\title{
Sleep patterns of infants in the first year of life
}

\author{
J EATON-EVANS AND A E DUGDALE \\ Human Nutrition Research Group, Department of Child Health, University of Queensland, Australia
}

SUMMARY A prospective study of 132 infants aged from 1 month to 1 year found that infants who were breast fed or breast plus bottle fed were significantly more likely to wake at night throughout the first year. Social class of the family, parity of the mother, and the weight gain of the infant had no consistent effects. This increased waking was not due to mothers of wakeful infants prolonging breast feeding to soothe their infants.

Many parents of young infants yearn for an uninterrupted night's sleep. ${ }^{1}$ Many infants sleep through the night by the age of 3 months and almost all by the age of 6 months, but waking may increase again during the second six months of life. ${ }^{2} 3$ Night waking has been associated with perinatal factors, ${ }^{24}$ colic or snoring, ${ }^{5}$ and temperament. ${ }^{6}$ Wright $e t a^{7}$ and also Elias et $a l^{8}$ reported that breast feeding for more than six months prolonged night time waking, but others reported no difference. ${ }^{19}$ Other authors have reported that parity, social class, the infant's birth weight, weight gain, and the age of starting non-milk foods did not affect waking at night. ${ }^{12} 4-671011$ In few of these studies, however, were the data analysed in a way that separated and assessed the independent effects of each of these factors.

We have used data from a prospective study of infants in south east Queensland to show the separate and independent effects of social and nutrition factors on the night waking of infants in the first year of life.

\section{Methods}

Four maternal and child health clinics were selected in Brisbane and Ipswich in south east Queensland so as to cover a range of social classes. Mothers with infants born in 1984 and attending these clinics were asked if they would participate in a one year study on the growth and feeding of their infants.

Mothers were interviewed at roughly monthly intervals from the time their infants were 1 month old. Mothers were asked about their social and family conditions at the first interview. During the first and subsequent interviews they were asked if their infants had had any health, feeding, or other problems during the previous month, what milk and other foods had been given, and whether they got up to their infants at night. The infants were weighed at each visit. Infants were considered to wake at night if one or both parents got up at night to the infant and then went back to bed. The data were grouped into intervals of three months $(1-3,3-6,6-9$, and 9-12 months). The milk feeds were classified as breast fed only, bottle fed only, breast plus bottle fed, or weaned from the breast. Infants were counted as having 'solids' if at any time during the three months period they were given non-milk foods. The weight for age of the infants and weight gains were calculated as a percentage of the $\mathrm{WHO} /$ $\mathrm{NCHS}^{12}$ standards using a computer programme which used exact ages and weights.

In these analyses mothers were divided into primiparas and multiparas. The occupations of husbands were used as an indicator of social class. In the analyses they have been divided into upper social class, which included managers, professionals, farmers, and technicians; and lower social class, which included skilled, semiskilled, and unskilled workers, and also the unemployed. ${ }^{13}$

The data were analysed by simple tabulation, $\chi^{2}$ tests, and by a multifactorial non-parametric method that separated the effects of different factors and tested the independent significance of each. ${ }^{14} 15$

\section{Results}

There were 132 infants and their mothers included in these analyses and 117 of these were followed up for the full 12 months.

PATTERNS OF WAKING AT NIGHT

At the age of 1 month, $82(62 \%)$ of the infants were waking more than once a night and a further 38 $(29 \%)$ were waking at night at least once a week (figure). By the age of 6 months, the number of 


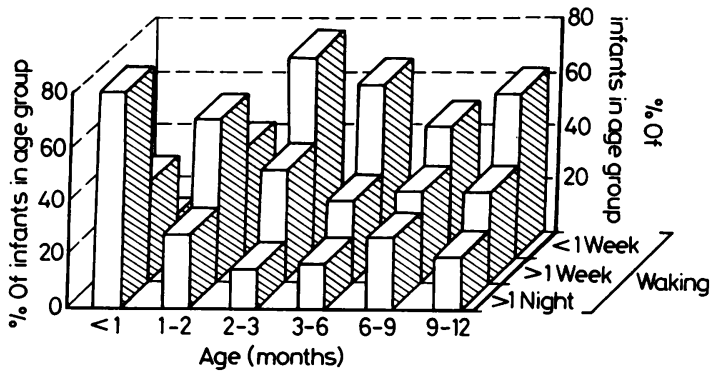

Figure Percentages of infants waking at night at different ages. The effects of feeding and other factors are not shown but are given in the text. The decline in the percentage of infants who regularly slept through the night is shown in the second half of the first year.

infants waking more than once a night had dropped to $15(13 \%)$ with a further $31(27 \%)$ waking at least once weekly. The proportion of infants waking at night increased significantly between 6 and 9 months of age $\left(\chi^{2}\right.$ test, $\left.\mathrm{p}<0.05\right)$.

At 1 and 2 months the median frequency of waking at night was about once a night. After 3 months the median frequency was between once a night and once a week. In the analyses that follow we have divided the infants into those who woke more frequently and those who woke less frequently than the median for age.

\section{FACTORS ASSOCIATED WITH FREQUENT WAKING AT NIGHT}

The multifactorial test was used to identify the separate factors associated with waking at night. The factors included in the analyses were the sex of the infant, the type of milk feeding (breast only, bottle only, breast plus bottle, but we excluded those weaned during the period), the giving of 'solid' non-milk foods, the percentage of expected weight gain during the previous three months, parity of the mother, and social class of the family. Venn diagrams tabulating these results are available from the authors. The results of these analyses are summarised in the table.

The sex of the infant, the parity of the mother, and the social class of the parents showed no significant effects in any of these analyses and therefore have not been included in the table. The type of milk feeding was the only factor that consistently showed significant differences in the first year of life. With one exception, which did not quite reach conventional levels of significance $(p=0.07)$, infants receiving breast milk, with or without other milk feeds, woke more at night than
Table Summary of factors associated with infants waking at night

\begin{tabular}{|c|c|c|}
\hline $\begin{array}{l}\text { Age } \\
\text { (months) }\end{array}$ & $\begin{array}{l}\text { Feeding of infants waking more } \\
\text { often than the median value } \\
\text { for age }(\%)\end{array}$ & $p$ Value \\
\hline$<1$ & $\begin{array}{l}\text { Breast }(67) v \text { bottle }(29) \\
\text { Breast + bottle }(89) v \text { bottle }(29) \\
\text { No infants on solids }\end{array}$ & $\begin{array}{l}<0.01 \\
<0.01\end{array}$ \\
\hline $1-3$ & $\begin{array}{l}\text { Breast }(49) v \text { bottle }(29) \\
\text { Breast + bottle }(52) v \text { bottle }(29) \\
\text { Solids (35) } v \text { no solids (57) } \\
\text { Weight gain }>100 \%(47) v \\
\quad \text { weight gain }<100 \% \text { (47) }\end{array}$ & $\begin{array}{l}\text { NS }(0 \cdot 07) \\
<0 \cdot 01 \\
0 \cdot 05\end{array}$ \\
\hline $3-6$ & $\begin{array}{l}\text { Breast (46) } v \text { bottle }(21) \\
\text { Breast + bottle }(56) v \text { bottle }(21) \\
\text { All infants had solids } \\
\text { Weight gain }>100 \%(26) v \\
\text { weight gain }<100 \%(55)\end{array}$ & $\begin{array}{r}0.01 \\
<0.01\end{array}$ \\
\hline $6-9$ & $\begin{array}{l}\text { Breast }(80) v \text { bottle }(50) \\
\text { Breast + bottle }(68) v \text { bottle }(50) \\
\text { All infants had solids } \\
\text { Weight gain }>100 \%(60) v \\
\text { weight gain }<100 \% \quad(60)\end{array}$ & $\begin{array}{l}0.02 \\
0.03\end{array}$ \\
\hline $9-12$ & $\begin{array}{l}\text { No infant exclusively breast fed } \\
\text { Breast + bottle (71) } v \text { bottle (37) } \\
\text { All infants had solids } \\
\text { Weight gain }>100 \% \text { (48) } v \\
\text { weight gain }<100 \% \text { (49) }\end{array}$ & 0.02 \\
\hline
\end{tabular}

those who did not receive breast milk. There were occasional significant differences with other factors, but these formed no pattern.

BREAST FEEDING AND WAKING AT NIGHT

We have shown that infants receiving breast milk were more likely to wake at night throughout the first year than those who did not receive breast milk, but this association does not necessarily imply a cause and effect relation. Mothers of wakeful babies may have prolonged breast feeding to help pacify their infants. If this were so, then mothers of wakeful infants should breast feed their infants longer than those whose infants are more settled.

To test this hypothesis we analysed the feeding history of infants who were breast fed at 1 month. Of the 61 infants who received breast milk at 1 month and woke frequently, $57(90 \%)$ were still breast fed at 3 months. Of the 33 'settled' infants who were breast fed at 1 month, $26(79 \%)$ were still breast fed at 3 months. Among the breast fed infants waking frequently at 3 months, $13(50 \%)$ were still breast fed at 6 months compared with $19(59 \%)$ who were waking infrequently at 3 months. None of these differences were significant. These findings do not support the hypothesis that mothers breast feed wakeful infants longer. 


\section{Discussion}

The group studied in this project was not a statistically random sample of the population but was selected to show how social and other factors might affect infant feeding and health. In a longitudinal study lasting one year there were inevitable drop outs. Most of these were caused by mothers moving to other areas or taking jobs. Each three month period, however, was analysed cross sectionally, so the analyses within each period should be valid.

Most infants wake at night in the first few months, but the proportion decreases until about 6 months of age. From then until 9 months the proportion of infants waking at night in our study increased again and then dropped slightly, but not significantly, from 9 months to 1 year. The lay explanation for this increased wakefulness is 'teething' but this must be regarded as an associated rather than a causal factor.

Using multifactorial methods which separate out the independent effects of each factor, we have found only one factor consistently associated with frequent waking at night, that is breast feeding. Our findings do not support the hypothesis that mothers of wakeful infants prolong breast feeding to soothe those infants back to sleep. ${ }^{16}$ There may be a physiological explanation for the increased wakefulness of breast fed infants. Breast milk leaves the stomach more rapidly than formula feeds ${ }^{17}$ and this could account for the shorter period of satiety and sleep in breast fed infants. The increased frequency of breast feeding should have biological advantages as frequent stimulation of the breast increases milk supply, but there are concomitant social disadvantages. The total intake of milk is not correlated with the frequency or duration of feeding of the infant. ${ }^{18}$

This study was funded by Wyeth Pharmaceuticals PLC.

We thank Dr P Livingstone, director general of health, Queensland department of health; Dr J MacFarlane, former director of the division of child health; the staff of the division and the nursing sisters at the maternal and child health clinics for help in all aspects of this study. We also thank the mothers who participated and answered our many questions.

\section{References}

${ }^{1}$ Beal VA. Termination of night feeding in infancy. $J$ Pediatr 1969;75:690-2.

${ }^{2}$ Moore T, Ucko LE. Night waking in early infancy. Part 1. Arch Dis Child 1957;32:333-42.

${ }^{3}$ Ferber R. Sleep, sleeplessness and sleep disruption in infants and young children. Ann Clin Res 1985;17:788-92.

${ }^{4}$ Bernal JF. Night waking in infants during the first 14 years. Dev Med Child Neurol 1973;15:760-9.

${ }^{5}$ Weissbluth M, Davis AT, Poncher J. Night waking in 4 to 8 month old infants. J Pediatr 1984;104:477-80.

6 Carey WB. Night waking and temperament in infancy. $J$ Pediatr 1974;84:756-8.

7 Wright P, MacLeod HA, Cooper MJ. Waking at night: the effect of early feeding experience. Child Care Health Dev 1983;9:309-19.

${ }^{8}$ Elias ED, Nicolson NA, Bora BA, Johnston J. Sleep/wake patterns of breast-fed infants in the first two years of life. Pediatrics 1986;77:322-9.

9 Jones BN, Ferreira MCR, Brown MF, Macdonald L. The association between perinatal factors and night waking. Dev Med Child Neurol 1978;20:427-34.

10 Grunwalt E, Bates T, Guthrie D. The onset of sleeping through the night in infancy. Relationship to introduction of solid food in the diet, birth weight and position in family. Pediatrics 1960;26:667-8.

1 Parmelee AH, Wenner WH, Schulz HR. Infant sleep patterns from birth to 16 weeks of age. J Pediatr 1964;65:576-82.

12 World Health Organisation. Measuring change in nutritional status. Geneva: WHO, 1983.

13 Congalton AA. Status and prestige in Australia. Melbourne: Cheshire, 1969.

14 Cochran WG. Some methods for strengthening the common Chi-squared tests. Biometrics 1954;10:417-51.

15 Dugdale AE. A simple method of analysing multifactorial data. Am J Clin Nutr 1975;28:788-92.

${ }^{16}$ Schmitt BD. Infants who do not sleep at night. Developmental and Behavioural Pediatrics 1981;2:20-3.

17 Barness NA. Infant feeding. In: Vaughan VC, McKay RJ, Behrman RE, eds. Nelson textbook of pediatrics. 11th ed. Philadelphia: WB Saunders, 1979:199.

${ }^{18}$ Butte NF, Wills C, Jean CA, Smith EO, Garza C. Feeding patterns of exclusively breast-fed infants during the first four months of life. Early Hum Dev 1985;12:291-300.

Correspondence to Dr AE Dugdale, Human Nutrition Research Group, c/o Department of Child Health, University of Queensland, St Lucia, Queensland 4067, Australia.

Accepted 7 January 1988 